\title{
Antioxidative effect of some hydroxy substituted aromatic bisimines
}

\author{
František Šeršeň ${ }^{1}$, Martin Walko ${ }^{2}$ and Dušan Loos ${ }^{3}$ \\ ${ }^{1}$ Institute of Chemistry, Faculty of Natural Sciences, Comenius University in Bratislava, Mlynská dolina CH2, 84215 \\ Bratislava, Slovakia \\ ${ }^{2}$ Institutue of Chemistry, Department of Organic Chemistry, Faculty of Science, Pavol Jozef Šafárik University in Košice, \\ Moyzesova 11, 04001 Košice, Slovakia \\ ${ }^{3}$ Department of Organic Chemistry, Faculty of Natural Sciences, Comenius University in Bratislava, Mlynská dolina CH2, \\ 84215 Bratislava, Slovakia
}

\begin{abstract}
This work deals with antioxidative properties of some derivatives 4,4'-bis(dihydroxybenzylanilidenamino)diphenylmethanes and diphenylethers, which structure is similar to resveratrol. Four derivatives of above-mentioned compounds were synthesized with hydroxyl $(\mathrm{OH})$ groups in various positions. It was found that derivatives with two $\mathrm{OH}$ groups in 2 and 5 positions were very good scavengers of 2,2-diphenyl-1-picrylhydrazyl (DPPH) radicals in both methanol and chloroform. On the other hand derivatives with $\mathrm{OH}$ groups in positions 2 and 4 did not scavenge DPPH radicals. The calculation of free enthalpies (by quantum chemical method AM1) necessary for the formations of anions or radicals support above mentioned findings because the enthalpies for effective derivatives were lesser, than for ineffective ones. Also, it was found that studied compounds did not scavenge hydroxyl radicals whereas resveratrol did it.
\end{abstract}

Key words: Antioxidant activity - Resveratrol analogues - Structural aspects

\section{Introduction}

The molecular structure of hydroxyl-substituted aromatic imines, which are the part of studied bis(dihydroxybenzylideneamino)diphenylmethanes and ethers is similar to resveratrol molecule. Resveratrol (trans-3,5,4'trihydroxystilbene) (I) is phytoalexin, which is produced by several plants (e.g. grape, eucalyptus, spruce, peanut, mulberry, lily, etc.). The highest amount of resveratrol was found in red grape skin. Recently, it has been published that resveratrol exhibits various biological, such as: anti-cancer, anti-viral, anti-inflammatory, sugar-lowering and anti-oxidative activities. It is known that resveratrol prolongs the life, and has a beneficial effect on liver and cardiovascular system (Celotti et al. 1996; Soleas et al. 1997; Gu et al. 2000; Kaeberlein et al. 2005). Therefore, resveratrol analogues are highly valuable target for synthesis and study of their physical, chemical and biological properties.

Correspondece to: František Šeršeň, Institute of Chemistry, Faculty of Natural Sciences, Comenius University in Bratislava, Mlynská dolina $\mathrm{CH} 2,84215$ Bratislava, Slovakia

E-mail: sersen@fns.uniba.sk
Imines are very common organic compounds used often as building blocks in organic synthesis (Layer 1963). Due to their properties they are widely used as ligands for metal complexation, liquid crystalline materials, and in analytical and medicinal chemistry (Alexander 1995). The traditional method of imine synthesis is based on heating of the mixture of an aldehyde with an amine in organic solvents (typically benzene or toluene), usually accompanied by an azeotropic removal of water (Layer 1963; Castellano et al. 1968; Taguchi and Westheimer 1971). Synthetic procedures replacing the organic solvent by water (Tanaka and Shiraishi 2000) or recyclable reaction medium such as poly(propyleneglycol) (van den Ancker et al. 2006) were described as a "green" alternatives to this process. However, the most effective and environmentally benign approach, which is used in this work, is to perform the reaction under solvent-less condition (Schmeyers et al. 1998; Tanaka and Toda 2000). In such a case the only by-product of the reaction is water and complete conversion alongside with high purity of product can be achieved.

The aim of this work is to investigate anti-oxidative activity of new bisimines, with molecular structure (Scheme 1) similar to that of resveratrol: 

(II),

4,4'-bis(2,4-dihydroxybenzylideneamino)diphenylmethane

4,4'-bis(2,5-dihydroxybenzylideneamino)diphenylmethane (III),

4,4'-bis(2,4-dihydroxybenzylideneamino)diphenyleter (IV),

4,4'-bis(2,5-dihydroxybenzylideneamino)diphenyleter (V).

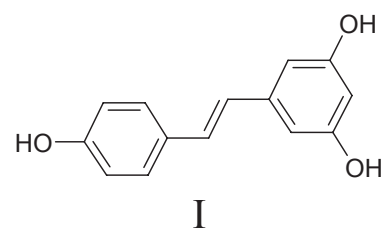<smiles>Oc1ccc(/C=N/c2ccc(Cc3ccc(/N=C/c4ccc(O)cc4O)cc3)cc2)c(O)c1</smiles><smiles>Oc1ccc(O)c(/C=N/c2ccc(Cc3ccc(/N=C/c4cc(O)ccc4O)cc3)cc2)c1</smiles>

III<smiles>Oc1ccc(/C=N/c2ccc(Oc3ccc(/N=C/c4ccc(O)cc4O)cc3)cc2)c(O)c1</smiles><smiles>Oc1ccc(O)c(/C=N/c2ccc(Oc3ccc(/N=C/c4cc(O)ccc4O)cc3)cc2)c1</smiles>

Scheme 1

\section{Materials and Methods}

Methanol, p.a., and chloroform, p.a., were purchased from Centralchem (Slovakia). 2,2-diphenyl-1-picrylhydrazyl (DPPH), 5,5-dimethyl-1-pyrroline N-oxide (DMPO) and 30\% $\mathrm{H}_{2} \mathrm{O}_{2}$ from Sigma (Germany). Aldehydes and diamines for the synthesis were purchased from Acros (Belgium) and $\mathrm{CDCl}_{3}$ and dimethyl- $\mathrm{d}_{6}$-sulfoxide (DMSO-D6) from Merck (Slovakia). UV-VIS spectra were measured using spectrophotometer
Genesys 6 (Thermo-Scientific, USA). The spectra of electron paramagnetic resonance (EPR) were recorded by the equipment ERS 230 (ZWG Akad. Wiss., Berlin, Germany), which operates in X-band $(\sim 9.3 \mathrm{GHz})$ at modulation amplitude $0.1 \mathrm{mT}$ and microwave power $5 \mathrm{~mW}$. Nuclear magnetic resonance (NMR) spectra were measured by the spectrometer Varian Mercury Plus $(400 \mathrm{MHz})$. All experiments were carried out at $25^{\circ} \mathrm{C}$.

The resveratrol analogues were prepared under solvent-less condition by grinding the mixture of $2 \mathrm{mmol}$ of the diamine and $4 \mathrm{mmol}$ of aldehyde in a mortar for $10 \mathrm{~min}$. Then the mixture was allowed to stand at room temperature for $48 \mathrm{~h}$ in order to achieve complete conversion. The yields were quantitative and the purity $>90 \%$. For further purification of the product and elimination of water resulting from the condensation reaction, crystallization from methanol or simple trituration in methanol (for compounds insoluble in methanol) was applied. The identity of synthesized compounds was confirmed by their ${ }^{1} \mathrm{H}$ - and ${ }^{13} \mathrm{C}-\mathrm{NMR}$ spectra in $\mathrm{CDCl}_{3}$ or $\mathrm{DMSO}_{6} \mathrm{D}_{6}$. The parameters of NMR spectra are presented below: (II)

4,4'-bis(2,4-dihydroxybenzylideneamino) diphenylmethane

${ }^{1} \mathrm{H}$ NMR (DMSO-D 6 , $\left.400 \mathrm{MHz}\right) \mathrm{d} 3.97$ (s, 2H), 6.29 (d, $J=$ $2.1 \mathrm{~Hz}, 2 \mathrm{H}), 6.40$ (dd, $J=8.5,2.1 \mathrm{~Hz}, 2 \mathrm{H}), 7.28$ (s, 8H), 7.40 (d, $J=8.5 \mathrm{~Hz}, 2 \mathrm{H}), 8.77$ (s, 2H), 10.25 (s, 2H), 13.61 (s, 2H).

${ }^{13}$ C NMR (DMSO-D $6,100.6 \mathrm{MHz}$ ) d 39.99, 102.31, 107.74, 111.99, 121.04, 129.59, 134.26, 139.34, 146.00, 162.00, $162.29,162.97$. (III)

4,4'-bis(2,5-dihydroxybenzylideneamino)diphenylmethane

${ }^{1} \mathrm{H}$ NMR (DMSO-D $\left.6,400 \mathrm{MHz}\right)$ d 3.97 (s, 2H), 6.30 (s, 2H), $6.40(\mathrm{~d}, J=8.5 \mathrm{~Hz}, 2 \mathrm{H}), 7.28(\mathrm{~s}, 8 \mathrm{H}), 7.41(\mathrm{~d}, J=8.5$ $\mathrm{Hz}, 2 \mathrm{H}), 8.77$ (s, 2H), 10.25 (s, 2H), 13.62 (s, 2H).

${ }^{13} \mathrm{C}$ NMR (DMSO-D $6,100.6 \mathrm{MHz}$ ) d 39.97, 102.30, $107.72,111.97,121.02,129.57,134.24,139.32,146.00,161.99$, $162.27,162.95$.

4,4'-bis(2,4-dihydroxybenzylideneamino)diphenylether (IV)

${ }^{1} \mathrm{H}$ NMR (DMSO-D, $\left.400 \mathrm{MHz}\right)$ d $6.30(\mathrm{~d}, J=1.6 \mathrm{~Hz}$, $1 \mathrm{H}), 6.40(\mathrm{dd}, J=2.1,8.5 \mathrm{~Hz}, 1 \mathrm{H}), 7.09(\mathrm{~d}, J=8.8 \mathrm{~Hz}, 2 \mathrm{H})$, $7.40(\mathrm{~d}, J=7.7 \mathrm{~Hz}, 2 \mathrm{H}), 7.42(\mathrm{~d}, J=8.2 \mathrm{~Hz}, 1 \mathrm{H}), 8.79(\mathrm{~s}, 1 \mathrm{H})$, $10.23(\mathrm{~s}, 1 \mathrm{H}), 13.52(\mathrm{~s}, 1 \mathrm{H})$.

${ }^{13}$ CNMR (DMSO-D $6,100.6 \mathrm{MHz}$ ) d 102.28, 107.74, 112.00, $119.35,122.56,134.22,143.68,154.99,161.91,162.24,162.74$.

4,4'-bis(2,5-dihydroxybenzylideneamino)diphenylether $(\mathrm{V})$

${ }^{1} \mathrm{H}$ NMR (DMSO-D $\left.6,400 \mathrm{MHz}\right) \mathrm{d} 6.79(\mathrm{~d}, J=8.8 \mathrm{~Hz}$, $1 \mathrm{H}), 6.86(\mathrm{dd}, J=2.9,8.8 \mathrm{~Hz}, 1 \mathrm{H}), 7.04(\mathrm{~d}, J=2.8 \mathrm{~Hz}, 1 \mathrm{H})$, $7.12(\mathrm{~d}, J=8.8 \mathrm{~Hz}, 2 \mathrm{H}), 7.46(\mathrm{~d}, J=8.8 \mathrm{~Hz}, 2 \mathrm{H}), 8.86(\mathrm{~s}, 1 \mathrm{H})$, $9.10(\mathrm{~s}, 1 \mathrm{H}), 12.27(\mathrm{~s}, 1 \mathrm{H})$.

${ }^{13} \mathrm{CNMR}\left(\mathrm{DMSO}_{6}, 100.6 \mathrm{MHz}\right) \mathrm{d} 116.79,117.05,119.23$, $119.38,120.86,122.98,143.90,149.53,152.91,155.40,162.32$. 
The anti-oxidative activity was tested by two methods:

i) The scavenging of DPPH radicals was carried out in the methanol and chloroform solutions according to Nagy et al. (2006). Briefly: Various amounts of studied compounds were added to DPPH solution, so that the final DPPH concentration was always $7 \times 10^{-5} \mathrm{~mol} / \mathrm{dm}^{3}$. A decrease of the intensity of DPPH absorption band at $517 \mathrm{~nm}$ was measured $30 \mathrm{~min}$ after addition of an antioxidant. The evaluation of the antioxidative efficiency was carried out from the linear part of the plot of absorbance vs. anti-oxidant concentration and is expressed as a $\mathrm{SC}_{50}$ values i.e. the concentration which caused $50 \%$ decrease of absorbance at $517 \mathrm{~nm}$.

ii) The scavenging of hydroxyl radicals $\left(\mathrm{HO}^{\circ}\right)$ was carried out according to Valentová et al. (2005). Briefly: Fenton reaction of $\mathrm{H}_{2} \mathrm{O}_{2}$ with $\mathrm{FeSO}_{4}$ and the spontaneous decomposition of $\mathrm{H}_{2} \mathrm{O}_{2}$ were used as sources of $\mathrm{HO}^{\circ}$. The scavenging activity of the tested samples was determined using EPR spectroscopy. Because $\mathrm{HO}^{\circ}$ are very unstable and cannot be detected readily by the continuous wave EPR spectrometer, a spin trap of DMPO was used to capture them, and the EPR spectra of this spin adduct were subsequently recorded. The reaction solution contained $5 \times 10^{-4} \mathrm{~mol} / \mathrm{dm}^{3}$ of $\mathrm{FeSO}_{4}, 0.025 \mathrm{~mol} / \mathrm{dm}^{3}$ of DMPO, the tested substances $\left(5 \mathrm{mg} / \mathrm{cm}^{3}\right)$, and $0.05 \mathrm{~mol} / \mathrm{dm}^{3}$ $\mathrm{H}_{2} \mathrm{O}_{2}$ in a phosphate buffer $\left(0.19 \mathrm{~mol} / \mathrm{dm}^{3} \mathrm{Na}_{2} \mathrm{HPO}_{4}, \mathrm{pH}\right.$ $=7.4$ ). The EPR spectra of these solutions were registered $20 \mathrm{~min}$ after the addition of $\mathrm{H}_{2} \mathrm{O}_{2}$. Due to low solubility of studied compounds, the efficiency of the $\mathrm{HO}^{\bullet}$ scavenge were determined only for their saturated solutions.

\section{Results and Discussion}

It was found that some derivatives of studied bisimines compounds are able to scavenge DPPH radicals in methanol
(Table 1). From this table, it is evident that some bisimine derivatives (II, IV) were ineffective. On the other hand, the other bisimine derivatives (III, V) exhibited very good antioxidative activity.

From Table 1 is evident that bisimine derivatives, which have hydroxyl $(\mathrm{OH})$ groups in 2 and 5 positions, are able to scavenge DPPH radicals 2-12 times (6-8 in methanol, 2-12 in cloroform) more effectively than resveratrol. On the other hand derivatives with $\mathrm{OH}$ groups in the position 2 and 4 do not scavenge DPPH radicals.

It is known, that the DPPH scavenging can be realized by several mechanism. The first mechanism goes through hydrogen radical $\left(\mathrm{H}^{*}\right)$ abstraction from an anti-oxidant molecule $(\mathrm{ArOH})$ according to the scheme: $\mathrm{R}^{\bullet}+\mathrm{ArOH} \rightarrow \mathrm{RH}+\mathrm{ArO}{ }^{\bullet}$ (Yokozawa et al. 1998), where $\mathrm{R}^{\bullet}$ is a radical and $\mathrm{RH}$ is its reduced form. This mechanism takes place in non-polar solvents, such as chloroform. The second mechanism runs by $\mathrm{H}^{+}$abstraction, which takes place in polar solvents such as methanol or ethanol (Foti et al. 2004). The third possibility of reaction DPPH with antioxidant molecule is a combination of both above-mentioned processes (Litwinienko and Ingold 2007). The other mechanism is realized trough the one-electron transfer from antioxidant to the radical $\left(\mathrm{R}^{\circ}+\mathrm{ArOH} \rightarrow \mathrm{R}^{-}+\mathrm{ArOH}^{\bullet+}\right)$ (Cheng et al. 2002; Leopoldini et al. 2004). Properties of antioxidant and solvent determine which mechanism takes place in the reaction of DPPH with an anti-oxidant.

The fact, that several studied bisimines scavenge DPPH radicals and other do not, can be explained by computations of free enthalpies for the formations of anions or radicals from antioxidant molecules. These computations were carried out by the quantum-chemical method AM1 (AMPAC 6. 7. 2001 Semichem, 7128 Summit, Shawnee, KS 66216) (Dewar et al. 1985). In Table 2 are presented values of free enthalpies for anion formation, after $\mathrm{H}^{+}$dissociation $\left(\Delta \mathrm{E}_{\mathrm{A}}\right)$

Table 1. $\mathrm{SC}_{50}$ values of the DPPH scavenging in methanol and chloroform

\begin{tabular}{|l|c|c|c|c|c|c|}
\hline Compound & I & II & III & IV & V & Solvent \\
\hline $\mathrm{SC}_{50}\left(\mu \mathrm{mol} / \mathrm{dm}^{3}\right)$ & 26.37 & ineffective & 4.11 & ineffective & 3.25 & methanol \\
\hline $\mathrm{r}^{2}$ & 0.998 & & 0.992 & & 0.998 & \\
\hline $\mathrm{SC}_{50}\left(\mu \mathrm{mol} / \mathrm{dm}^{3}\right)$ & 120.83 & ineffective & 62.90 & ineffective & 10.17 & chloroform \\
\hline $\mathrm{r}^{2}$ & 0.986 & & 0.974 & & 0.997 & \\
\hline
\end{tabular}

$\mathrm{SC}_{50}$, concentration which caused $50 \%$ decrease in $\mathrm{DPPH}$ absorbance at $517 \mathrm{~nm} ; \mathrm{r}^{2}$, the average square deviation.

Table 2. Free enthalpies for anion or radical formations of studied imines

\begin{tabular}{|c|c|c|c|c|}
\hline Compound & $\Delta \mathrm{E}_{\mathrm{A}}(\mathrm{kJ} / \mathrm{mol})$ & $\Delta \mathrm{E}_{\mathrm{R}}(\mathrm{kJ} / \mathrm{mol})$ & $\mathrm{IP}(\mathrm{kJ} / \mathrm{mol})$ & $\mathrm{IP}(\mathrm{eV})$ \\
\hline II & 158.10 & 166.56 & 838.70 & 8.69 \\
\hline III & 121.15 & 140.49 & 831.82 & 8.62 \\
\hline IV & 164.48 & 166.62 & 824.76 & 8.55 \\
\hline V & 130.01 & 139.79 & 826.14 & 8.56 \\
\hline
\end{tabular}

$\Delta \mathrm{E}_{\mathrm{i}}$, energy differences among ground and anionic or radical states of studied molecules; IP, ionization potentials of studied imines. 
and radical formation after $\mathrm{H}^{\bullet}$ abstraction $\left(\Delta \mathrm{E}_{\mathrm{R}}\right)$. From data presented in Table 2 is evident that the bisimine derivatives with $\mathrm{OH}$ groups in 2,5 positions need less energy for the formations of anions or radicals as those with $\mathrm{OH}$ groups in 2,4 positions. Also the fact, that $\Delta \mathrm{E}_{\mathrm{A}}<\Delta \mathrm{E}_{\mathrm{R}}$ for equivalent derivatives support our finding that studied bisimines exhibit higher DPPH scavenging in methanol then in chloroform. On the base of these findings we suggest that the scavenging DPPH radicals take place through $\mathrm{H}^{+}$dissociation. This assumption support also the literature data (http:/www. zirchrom.com/organic.htm, 2008) of pKa values for 1,4dihydroxybenzene (10.35) and for 1,3-dihydroxybenzene (9.81), which are a part of compounds under study. Also these findings support the assumption that studied bismines with $\mathrm{OH}$ groups in 2,5 positions will be easier release $\mathrm{H}^{+}$as those with $\mathrm{OH}$ groups in 2,4 positions. So as we are found, whether DPPH scavenging take place through the oneelectron transfer mechanism, ionization potentials (IP) of studied bisimines were calculated (Table 2, columns 4 and 5). From these data is evident that correlation among IPs and DPPH scavenging is not fully good. All above-mentioned calculations support our results that derivatives with $\mathrm{OH}$ groups in 2,5 positions are better antioxidants as ones with $\mathrm{OH}$ groups in 2,4 positions.

As the scavenging of DPPH takes place also in aprotic solution (in chloroform), we suppose the mechanism involves $\mathrm{H}^{*}$ abstraction from bisimine molecule, according to mechanism, which was suggested by Foti et al. (2004). Therefore, we can predict that the compounds under study would be able to scavenge also $\mathrm{HO}^{*}$. The experiments with scavenging of $\mathrm{HO}^{\circ}$ show that lower amount of $\mathrm{DMPOOH}^{\circ}$ adduct was registered in the presence of studied compounds if $\mathrm{HO}^{\circ}$ were generated by Fenton reaction. On the other hand, the unchanged amount of $\mathrm{DMPOOH}^{\circ}$ was registered if $\mathrm{HO}^{\circ}$ were generated by the spontaneous $\mathrm{H}_{2} \mathrm{O}_{2}$ decomposition. On the base of these findings we assume that studied bisimine derivatives do not scavenge $\mathrm{HO}^{*}$. The lower amount of $\mathrm{DMPOOH}^{*}$ registered in Fenton reaction is caused by lower amount of generated $\mathrm{HO}^{*}$ due to the complex formation of bisimine molecules with $\mathrm{Fe}^{2+}$.

\section{Conclusion}

It was found that some of the newly synthesized resveratrol analogues are very good scavengers of DPPH radicals, even better (compounds III and V) than natural resveratrol. On the other hand the compounds II and IV do not scavenge the DPPH radicals. The factor determining efficiency of the scavenging of DPPH radicals are the positions of the $\mathrm{OH}$ groups in the antioxidant molecule. Compounds bearing two hydroxyl groups in the para position to each other are very effective scavengers, because their oxidized form can be stabilized through isomerization to a quinoid structure.

Acknoledgement. This work was supported by grants of Ministry of Education, Slovak Republic, VEGA 1/3411/06 and 1/4470/07.

\section{References}

Alexander W. (1995): Design and synthesis of macrocyclic ligands and their complexes of lanthanides and actinides. Chem. Rev. 95, 273-342; doi:10.1021/cr00034a002

Castellano J. A., Goldmacher J. E., Barton L. A., Kane J. S. (1968): Liquid crystals. II. Effects of terminal group substitution on the mesomorphic behavior of some benzylideneanilines. J. Org. Chem. 33, 3501-3504; doi:10.1021/ jo01273a030

Celotti E., Ferrarini R., Zironi R., Conte L. S. (1996): Resveratrol content of some wines obtained from dried Valpolicella grapes: Recioto and Amarone. J. Chromatogr., A 730, 4752; doi:10.1016/0021-9673(95)00962-0 PMid:8680595

Cheng Z., Ren J., Li Y., Chang W., Chen Z. (2002): Study on the multiple mechanisms underlying the reaction between hydroxyl radical and phenolic compounds by qualitative structure and activity relationship. Bioorg. Med. Chem. 10, 4067-4073; doi:10.1016/S0968-0896(02)00267-5

Dewar M. J. S., Zoebisch E. G., Healy E. F., Stewart J. J. P. (1985): Development and use of quantum-mechanical molecular models. 76. AM1: a new general-purpose quantummechanical molecular model. J. Am. Chem. Soc. 107, 3902-3909; doi:10.1021/ja00299a024

Foti M. C., Daquino C., Geraci C. (2004): Electron-transfer reaction of cinnamic acids and their methyl esters with the DPPH center dot radical in alcoholic solutions J. Org. Chem. 69, 2309-2314; doi:10.1021/jo035758q PMid:15049623

Gu X. L., Chub Q. Y., O’Dwyer M., Zeece M. (2000): Analysis of resveratrol in wine by capillary electrophoresis. J. Chromatogr., A 881, 471-481; doi:10.1016/S00219673(00)00211-9 PMid:10905729

Kaeberlein M., McDonagh T., Heltweg B., Hixon J., Westman E. A., Caldwell S. D., Napper A., Curtis R., DiStefano P. S., Fields S., Bedalov A., Kennedy B. K. (2005): Substratespecific activation of sirtuins by resveratrol. J. Biol. Chem. 280, 17038-17045; doi:10.1074/jbc.M500655200 PMid:15684413

Layer R. W. (1963): The chemistry of imines. Chem. Rev. 63, 489-510; doi:10.1021/cr60225a003

Leopoldini M., Marino T., Russo N., Toscano M. (2004): Antioxidant properties of phenolic compounds: $\mathrm{H}$-atom versus electron transfer mechanism. J. Phys. Chem. A. 108, 4916-4922; doi:10.1021/jp037247d

Litwinienko G., Ingold K. U. (2007): Solvent effects on the rates and mechanisms of reaction of phenols with free radicals. Acc. Chem. Res. 40, 222-230; doi:10.1021/ar0682029 PMid:17370994

Nagy M., Špilková J., Vrchovská V., Kontšeková Z., Šeršeň F., Mučaji P., Grančai D. (2006): Free radical scavenging 
activity of different extracts and some constituents from the leaves of Ligustrum vulgare and L. delavayanum. Fitoterapia 77, 395-397; doi:10.1016/j.fitote.2006.04.010 PMid:16797145

Schmeyers J., Toda F., Boy J., Kaupp G. (1998): Quantitative solidsolid synthesis of azomethines. J. Chem. Soc., Perkin Trans. 2, 989-993; doi:10.1039/a704633b

Soleas G. J., Diamandis E. P., Goldberg D. M. (1997): Resveratrol: a molecule whose time has come? And gone? Clin. Biochem. 30, 91-113; doi:10.1016/S0009-9120(96)00155-5 PMid:9127691

Taguchi K., Westheimer F. H. (1971): Catalysis by molecular sieves in preparation of ketimines and enamines. J. Org. Chem. 36, 1570-1572; doi:10.1021/jo00810a033

Tanaka K., Shiraishi R. (2000): Clean and efficient condensation reaction of aldehydes and amines in a water suspension medium. Green Chem. 2, 272-273; doi:10.1039/ b006424f
Tanaka K., Toda F. (2000): Solvent-free organic synthesis. Chem. Rev. 100, 1025-1074; doi:10.1021/cr940089p PMid:11749257

Valentová K., Šeršeň F., Ulrichová J. (2005): Radical scavenging and anti-lipoperoxidative activities of Smallanthus sonchifolius leaf extracts. J. Agric. Food Chem. 53, 5577-5582; doi:10.1021/jf050403o PMid:15998117

van den Ancker T. R., Cave G. W. V., Raston C. L. (2006): Benign approaches for the synthesis of bis-imine Schiff bases. Green Chem. 8, 50-53; doi:10.1039/b513289d

Yokozawa T., Chen C. P., Dong E., Tanaka T., Nonaka G. I., Nishioka I. (1998): Study on the inhibitory effect of tannins and flavonoids against the 1,1-diphenyl-2-picrylhydrazyl radical. Biochem. Pharmacol. 56, 213-222; doi:10.1016/ S0006-2952(98)00128-2 PMid:9698075

Received: January 15, 2009

Final version accepted: April 8, 2009 